\title{
Antimicrobial and antioxidant potential of different solvent extracts of the medicinal plant Geum urbanum L.
}

\author{
Lyudmila Dimitrova', Maya M. Zaharieva', Milena Popova², Nedelina Kostadinova', Iva Tsvetkova', \\ Vassya Bankova ${ }^{2^{*}}$ (D) and Hristo Najdenski
}

\begin{abstract}
Many Geum species are known to be rich in biologically active compounds and therefore could be a source of new natural products with pharmacological potential. The medicinal plant Geum urbanum L. is widespread in Bulgaria and has been used in folk medicine. In the present study, the methanol extracts of the roots and aerial parts of $G$. urbanum and their fractions (petroleum ether, ethyl acetate and $n$-butanol) were investigated for antibacterial and radical scavenging activity. The ethyl acetate and $n$-butanol fractions inhibited the growth of Gram-positive pathogenic and opportunistic bacteria from the genus Staphylococcus (MIC EtOAc: $0.078 \mathrm{mg} / \mathrm{ml}$ aerial and $0.156 \mathrm{mg} / \mathrm{ml}$ roots; MIC n-BuOH: $0.156 \mathrm{mg} / \mathrm{ml}$ aerial and $1.25 \mathrm{mg} / \mathrm{ml}$ roots) and the species Bacillus cereus stronger than the other extracts and fractions tested (MIC EtOAc: $0.078 \mathrm{mg} / \mathrm{ml}$ aerial and $0.156 \mathrm{mg} / \mathrm{ml}$ roots; $\mathrm{MIC}$-BuOH: $0.156 \mathrm{mg} / \mathrm{ml}$ aerial and $0.078 \mathrm{mg} / \mathrm{ml}$ roots), and showed corresponding radical scavenging activity (EtOAc: $\mathrm{EC}_{50} 1.5 \mu \mathrm{g} / \mathrm{ml}$ aerial, $0.8 \mu \mathrm{g} /$ $\mathrm{ml}$ roots; $n$-BuOH: $4.5 \mu \mathrm{g} / \mathrm{ml}$ aerial; $3.7 \mu \mathrm{g} / \mathrm{ml}$ roots). Additionally, their total phenolic content was quantified (\% of dry EtOAc fractions of roots $61 \%$, of arial parts $32 \%$; of dry $n-\mathrm{BuOH}$ fractions of roots $16 \%$, of arial parts $13 \%$ ). Seven compounds were isolated and identified spectroscopically from the ethyl acetate extract. Two acetylated ellagic acid rhamnosides were found for the first time in the genus Geum and three others, tormentic acid, niga-ichigoside F1, and 3,3'-di-O-methylellagic acid-4-O- $\beta$-D-glucopyranoside, were newly detected for the species $G$. urbanum. Our results reveal that $G$. urbanum $L$. is a perspective medicinal plant and deserves further, more detailed studies.
\end{abstract}

Keywords: Geum urbanum L., Plant extracts, Antibacterial activity, Minimal inhibitory concentration, Radical scavenging activity, Phenolics

\section{Introduction}

The genus Geum (Rosaceae) consists of about 70 plant species distributed in temperate regions [1]. Many Geum species are rich in biologically active compounds and therefore could be a source of new plant products with pharmacological potential. Eight of them are part of the Bulgarian flora [2], among which the medicinal plant Geum urbanum L. is widespread over the territory of the country. This herbaceous perennial plant species commonly known as wood avens or St. Benedict's herb [3]

\footnotetext{
*Correspondence: bankova@orgchm.bas.bg

${ }^{2}$ Institute of Organic Chemistry with Centre of Phytochemistry, Bulgarian

Academy of Sciences, Acad. G. Bonchev Str. BI.9, 1113 Sofia, Bulgaria

Full list of author information is available at the end of the article
}

has been recommended since ancient times in the folk medicine for treating of gastro-intestinal diseases, disorders of the liver, biliary tract and uterus, as well as against hemorrhoids $[4,5]$. The roots and rhizomes decoction has been applied for the treatment of diarrhoea, dysentery, dyspepsia, gastroenteritis, whereas the aerial parts infusion was used in cases of leucorrhoea, haemorrhages and fever [4]. The infusion is ingested against rheumatism, gout, infections and fever [6]. The ethnopharmacological data suggest antimicrobial and radical scavenging properties of the extracts. It is well established that infectious diseases can provoke oxidative stress events in the human body, because reactive oxygen and nitrogen radicals secreted by bacterial pathogens accumulate in the microenvironment of affected tissues. In this case, 
the antioxidant system of the human body could not act adequately to prevent various oxidative damages. Some studies have even suggested that bactericidal antibiotics may increase the oxidative stress via the Fenton reaction, though this finding remains controversial [7]. Therefore, one of the important points today is to focus on investigation of plants that not only possess strong antioxidant properties but also exhibit antimicrobial activity $[8,9]$.

More than 200 compounds (monoterpenoids, sesquiterpens, triterpenoids, flavonoids, hydrolysable tannins, phenylpropanoids and others) have been isolated from the genus Geum after 1920 [1], but the studies in chemical composition of G. urbanum are limited: a few articles have been published on the isolation of chemical constituents of G. urbanum. From the roots, the rare disaccharide vicianose [10], the phenylpropanoid gein [11], catechin, gallic acid, galloylglucose, caffeic acid, chlorogenic acid and ellagic acid [12] were identified. More recently, ellagitannins and procyanidins were isolated from roots of G. urbanum [3, 13]. Essential oils from aerial and underground parts of the plant have also been studied [14].

To our knowledge, data concerning the antimicrobial and radical scavenging potential of G. urbanum in relation to its chemical composition have not been reported. Thus, in the present study we aimed to investigate the antibacterial and radical scavenging activity of extracts and fractions obtained from aerial and underground parts of G. urbanum, to determine the total phenolic content and to isolate some individual chemical compounds.

\section{Materials and methods Plant material}

Dry roots and aerial parts from Geum urbanum were commercial products, produced by Sunny-Yambol, Ltd ${ }^{\circledR}$, according to the lable it was collected in April 2014 from district of Stara Zagora, Bulgaria.

\section{Extraction and solvent fractionation}

Five hundred g roots and $500 \mathrm{~g}$ aerial parts of G. urbanum were extracted by maceration each in 31 methanol for 2 days at room temperature, the extracts were filtered and the extraction was repeated. The total $\mathrm{MeOH}$ extracts were concentrated in vacuo, and extracted successively with petroleum ether, ethyl acetate (EtOAc) and $n$-butanol $(n-\mathrm{BuOH})$. The fractions obtained from aerial parts were evaporated to give $7.9 \mathrm{~g}$ petroleum ether; $10.4 \mathrm{~g}$ EtOAc and $17.82 \mathrm{~g} n$-BuOH dry residue, and from roots, $1.9 \mathrm{~g}$ petroleum ether; $14.1 \mathrm{~g}$ EtOAc and $14.8 \mathrm{~g} n$ - $\mathrm{BuOH}$ dry residue. Parts of the total $\mathrm{MeOH}$ extracts was evaporated to dryness and used in other experiments.

\section{Antibacterial activity}

\section{Test microorganisms}

The test bacteria used for antimicrobial susceptibility testing were: Staphylococcus aureus NBIMCC 3359 (National Bank for Industrial Microorganisms and Cell Cultures, Bulgaria), Staphylococcus aureus ATCC 3865 (American Type Cell Culture Collection, USA), methicillin-resistant Staphylococcus aureus (MRSA) NBIMCC 8327, Staphylococcus epidermidis NBIMCC 1093, Streptococcus pyogenes SAIM 10535 (Collection of the Stephan Angeloff Institute of Microbiology, Bulgaria), Bacillus cereus ATCC 9634, Bacillus subtilis SAIM 1A95, Listeria monocytogenes SAIM C12, Escherichia coli SAIM WF+, Pseudomonas aeruginosa NCTC 6749 (National Collection of Type Cultures, England), Salmonella typhimurium SAIM 123 and Candida albicans SAIM 562.

\section{Culture medium and growth conditions}

For each bacterium used in this study Muller Hinton agar (MHA) and broth (MHB) (CM0337B, resp. CM0405B, Thermo Scientific-Oxoid, UK) were applied. SabouraudGlucose agar supplemented with gentamicin $(40 \mu \mathrm{g} / \mathrm{ml})$ (CM0041, Oxoid, Basingstoke, UK) was used as culture medium for $C$. albicans. All microorganisms were grown at $37{ }^{\circ} \mathrm{C}$ overnight except $B$. cereus ATCC 9634, which was grown at $30^{\circ} \mathrm{C}$.

\section{Minimal inhibitory (MIC) and bactericidal (MBC) concentrations}

The antimicrobial activity was estimated by the broth microdilution method according to CLSI procedures [15] as published before [16]. Briefly, bacterial inoculums with concentration $10^{5} \mathrm{CFU} / \mathrm{ml}$ were added to microtitre trays containing $\mathrm{MHB}$ loaded with G. urbanum $\mathrm{MeOH}$ extracts and fractions or single compounds in concentrations varying from 0.039 to $2.5 \mathrm{mg} / \mathrm{ml}$. Plates were incubated at $37^{\circ} \mathrm{C}$ for $18 \mathrm{~h}$. The negative control was prepared by spreading $10 \mu \mathrm{l}$ of the inoculation-suspension on a nutrient agar plate and incubated at $37^{\circ} \mathrm{C}$ overnight. Gentamicin was used as reference antibiotic according to the requirements of EUCAST. Experiments were performed in triplicate. MIC were determined visually as the lowest concentration without visible growth [17]. $\mathrm{MBC}$ were determined by overnight incubation on MHA of $100 \mu \mathrm{l}$ from the untreated control and samples treated with $1 / 2 \times$ MIC, MIC and $2 \times$ MIC for further $18 \mathrm{~h}$ at $37^{\circ} \mathrm{C}$. MBC were read as concentrations where no bacterial growth occurred on the agar plates [17].

\section{Dehydrogenase (DEHA) activity}

The DEHA activity of the test microorganisms was assessed by spectrophotometric analysis [18]. For the 
latter treated and untreated bacterial cells were incubated for $60 \mathrm{~min}$ at $37^{\circ} \mathrm{C}$ with MTT dye (3-(4,5-dimethylthiazolyl-2)-2,5-diphenyltetrazolium bromide, M2128-1G, Sigma-Aldrich) in final concentration $0.05 \mathrm{mg} / \mathrm{ml}$. Formazan crystals were dissolved by an equivalent volume of $5 \% \mathrm{HCOOH}$ in isopropanol. Absorption was measured with an ELISA reader (BioTek Elx800, USA) at $550 \mathrm{~nm}$ (reference $690 \mathrm{~nm}$ ) against a blank solution. As far as some of the tested extracts, fractions and compounds possess polyphenolic hydroxyl groups reducing the MTT dye [19-21], their own absorbance was measured in parallel, in the absence of bacterial inoculum.

\section{Time-kill effect}

Assays for the rate of killing effect was carried out for EtOAc fractions from roots and aerial parts against $B$. cereus ATCC 9634 by using a protocol of Olajuyigbe and Afolayan [22]. overnight culture (10 ml MHB) was spectrophotometric measurement at $600 \mathrm{~nm}$ and diluted to $10^{5} \mathrm{CFU} / \mathrm{ml}$ bacteria concentration. The experiment was performed into 96-well microplate. The bacterial inoculums were added to each well containing MHB loaded with G. urbanum EtOAc fractions in concentrations 2.5, 1.25 and $0.625 \mathrm{mg} / \mathrm{ml}$. The final volume of each sample was $100 \mu \mathrm{l} /$ well. The plate was incubated at $30^{\circ} \mathrm{C} .100 \mu \mathrm{l}$ aliquot was transferred from each well onto petri dishes with $20 \mathrm{ml}$ MHA at $0,4,12$ and $24 \mathrm{~h}$ and incubated at $30^{\circ} \mathrm{C}$ overnight.

\section{Radical scavenging activity DPPH• assay}

Each extract and fraction was evaluated for the radical scavenging ability for using of the bleaching level of purple colored solution of 1,1-diphenyl-2-picrylhydrazyl $(\mathrm{DPPH} \bullet)_{-}$-stable radical used as a reagent, according to the method of Murthy et al. [23] with small modifications. Various concentrations of the plant extracts and fractions were added to $1 \mathrm{ml}$ of DPPH $(100 \mu \mathrm{M})$ solution in ethanol. The absorbance was read against a blank at $517 \mathrm{~nm}$, after $30 \mathrm{~min}$ incubation period at $37^{\circ} \mathrm{C}$. Inhibition of free radical DPPH• in percent was calculated according to the formula:

$$
\text { Inhibition } \%=\left(\mathrm{A}_{\text {blank }}-\mathrm{A}_{\text {sample }} / \mathrm{A}_{\text {blank }}\right) \times 100,
$$

where $A_{b l a n k}$ is the absorbance of the control reaction (containing all the reagents except the test compound) and $\mathrm{A}_{\text {sample }}$ is the absorbance of the test compound. The concentration of the $\mathrm{MeOH}$ extracts and fractions providing $50 \%$ inhibition $\left(\mathrm{IC}_{50}\right)$ was calculated on the basis of graph plot-inhibition percentage against extract or fraction concentration $(0.5,1.0,2.5,5.0,10.0,25.0,50.0 \mu \mathrm{g} /$ $\mathrm{ml})$. Caffeic acid was used as a positive control.

\section{Superoxide anion scavenging activity}

Determination of superoxide anion scavenging activity was done by inhibition of nitro blue tetrazolium (NBT) reduction by photochemically generated $\mathrm{O}_{2}{ }^{-}$[24]. Samples were prepared to contain $5 \mu \mathrm{g} / \mathrm{ml}$ of the corresponding preparations (Fig. 3). The reaction mixture contained $56 \mu \mathrm{M}$ NBT, $0.01 \mathrm{M}$ methionine, $1.17 \mu \mathrm{M}$ riboflavin, $20 \mu \mathrm{M} \mathrm{NaCN}$ and $0.05 \mathrm{M}$ phosphate buffer with a pH of 7.8. Superoxide presence was evaluated by the increase in absorbance at $560 \mathrm{~nm}$ at $30^{\circ} \mathrm{C}$ after $6 \mathrm{~min}$ of incubation from the beginning of the illumination. The dosedependence of the superoxide anion scavenging effect of extracts, fractions and caffeic acid (reference substance) was calculated against different concentrations $(1,2,3$, $4,5,10,25,50 \mu \mathrm{g} / \mathrm{ml})$. All values were the mean of three measurements and expressed as mean $\pm \mathrm{SD}$.

\section{Quantification of total phenolics}

To determine the amount of polyphenol compounds in $\mathrm{MeOH}$ extracts $1 \mathrm{~g}$ dry mass was extracted twice with $\mathrm{MeOH}, 1: 10(\mathrm{w} / \mathrm{v})$ under ultrasound conditions at $50{ }^{\circ} \mathrm{C}$ for $1 \mathrm{~h}$. The extracts obtained after filtration were combined in a $25 \mathrm{ml}$ volumetric flask and diluted with $\mathrm{MeOH}$. Dry extracts of the petroleum ether $(50 \mathrm{mg})$, EtOAc (50 mg) and $n-\mathrm{BuOH}(200 \mathrm{mg})$ fractions were dissolved in $\mathrm{MeOH}$ in $25 \mathrm{ml}$ volumetric flasks. For every extract and fraction, the procedures were performed in triplicates.

An aliquot $(3 \mathrm{ml})$, were transferred in a $25 \mathrm{ml}$ volumetric flask and diluted with $\mathrm{MeOH}$ except of petroleum ether fraction which were diluted to $5 \mathrm{ml}$. All final solutions were subjected to spectrophotometric analysis.

Methanolic solutions of gallic acid (from 0.2 to $0.0125 \mathrm{mg} / \mathrm{ml}$ ) were used to generate the standard curve. To $5 \mathrm{ml}$ distilled water, $0.5 \mathrm{ml}$ of the standard solution were added, after that $2 \mathrm{ml}$ of Folin-Ciocalteu reagent and $3 \mathrm{ml}$ of $20 \% \mathrm{Na}_{2} \mathrm{CO}_{3}$ were added and the volume made up to $25 \mathrm{ml}$ (volumetric flask). After $2 \mathrm{~h}$ the absorbance was measured at $760 \mathrm{~nm}$ (blank prepared in the same way, $0.5 \mathrm{ml}$ of $\mathrm{MeOH}$ instead of standard solution). For the analysis of the plant extracts and their fractions, $0.5 \mathrm{ml}$ of the corresponding solution was applied in the same procedure. Every analysis was performed in triplicate.

\section{Isolation of chemical constituents of EtOAc fraction from roots}

Fourteen grams of EtOAc fraction from the roots were subjected to vacuum liquid chromatography on silica gel using a $\mathrm{CHCl}_{3}-\mathrm{MeOH}$ gradient system to give 12 subfractions (A-L). Subfractions from $B$ to $E$ were combined in $\mathrm{BE}(1.35 \mathrm{~g})$ and subjected to column chromatography 
(CC) on silica gel using a $\mathrm{CHCl}_{3}-\mathrm{MeOH}$ gradient system to give 15 subfractions (BE1-BE15). Subfraction BE5 was subjected to CC on Sephadex LH-20 using a $\mathrm{CHCl}_{3}-\mathrm{MeOH}$ gradient system to obtain tormentic acid 1 (8.6 mg) [25]. Subfractions BE8-BE10 were combined $(70 \mathrm{mg})$ and subjected to preparative thin-layer chromatography (TLC) with EtOAc-MeOH (25:1) as a mobile phase to obtain two compounds: 3-O-methylellagic acid-3'-O- $\alpha-3^{\prime \prime}-O$-acetylrhamnopyranoside 2 (14 mg) and 3-O-methylellagic acid-3'-O- $\alpha-2^{\prime \prime}-O-$ acetylrhamnopyranoside $3(15 \mathrm{mg})$ [26].

Subfractions F and G were combined in FG (4.39 g) to give 26 subfractions. Subfraction FG9 was subjected to $\mathrm{CC}$ on silica gel using a $\mathrm{CHCl}_{3}-\mathrm{MeOH}-\mathrm{H}_{2} \mathrm{O}$ gradient system to give 13 subfractions. Subfraction FG9-3 was subjected to preparative TLC with EtOAc- $\mathrm{MeOH}$ (15:1) as a mobile phase to obtain cathechin 4 (6.4 mg) [27]. Subfractions from FG9-7 to FG9-12 were combined $(20 \mathrm{mg})$ and subjected to $\mathrm{CC}$ on silica gel using a $\mathrm{CHCl}_{3}-$ $\mathrm{MeOH}$ gradient system to obtain 3,3'-di-O-methylellagic acid-4-O- $\beta$-D-glucopyranoside 5 (3.8 mg) [28]. Subfraction FG11 was subjected to CC on Sephadex LH-20 using $\mathrm{MeOH}$ as a mobile phase to give 9 subfractions. Subfraction FG11-1 was purified by CC on Sephadex LH-20 to obtain niga-ichigoside F1 6 (31 mg) [27]. Subfraction FG12 was subjected to CC on Sephadex LH-20 using $\mathrm{MeOH}$ as a mobile phase to give 10 subfractions. Subfraction FG12-2 was gein 7 (31.4 mg) [27].

The structures of the isolated compounds, tormentic acid 1, 3-O-methylellagic acid-3'-O- $\alpha-3^{\prime \prime}-O$-acetylrhamnopyranoside 2, 3-O-methylellagic acid-3'-O- $\alpha-2^{\prime \prime}-O-$ acetylrhamnopyranoside 3 , catechin $4,3,3^{\prime}$-di-O-methylellagic acid-4- $O-\beta$-D-glucopyranoside 5 , niga-ichigoside F1 $\mathbf{6}$, and gein 7 , (Fig. 1) were identified by means of NMR spectral data (1D and 2D) and comparison with literature data. All chemicals and solvents were of analytical grade. NMR spectra were recorded on Bruker AV 600 spectrometer (600 MHz for ${ }^{1} \mathrm{H}$ and $150 \mathrm{MHz}$ for ${ }^{13} \mathrm{C}$ ).

\section{Results \\ Antibacterial activity \\ $M I C, M B C$ and DEHA activity}

$\mathrm{MeOH}$ extracts and petroleum ether, EtOAc and $n-\mathrm{BuOH}$ fractions of the $\mathrm{MeOH}$ extracts from underground and aerial parts of G. urbanum were investigated. All extracts and fractions displayed varying antibacterial activity against S. aureus NBIMCC 3359, S. aureus ATCC 6538 P, MRSA NBIMCC 8327, S. epidermidis NBIMCC 1093 and B. cereus ATCC 9634 in concentration range $0.039-2.5 \mathrm{mg} / \mathrm{ml}$. No activity was found against $L$. monocytogenes SAIM C12, $S$. pyogenes SAIM 10535, B. subtilis SAIM 1A95, E. coli SAIM WF+, P. aeruginosa NCTC 6749, S. typhimurium SAIM 123 and C. albicans SAIM 562. The results are listed in Table 1.
The lowest MIC values were demonstrated by the EtOAc fractions from aerial and parts and roots of the plant $(0.039-1.25 \mathrm{mg} / \mathrm{ml})$ against five strains Gram-positive test bacteria. Petroleum ether fractions had the lowest activities against test bacteria $(1.25-2.5 \mathrm{mg} / \mathrm{ml}$ and more). Additionally, the values of respiratory activity were determined for all MIC and MBC. Aiming to detect the metabolic activity of bacteria treated with different fractions, a MTT assay was performed. The DEHA activity test is based on the principle that DEHA enzymes are produced by all living cells and this assay can be related to the number of live cells present [29] (results in Table 1). The EtOAc fractions showed lowest value of respiratory activity against $B$. cereus ATCC $9634(0-1.9 \%)$ in concentrations $0.625 \mathrm{mg} / \mathrm{ml}$. In cases where no inhibitory or bactericidal effect was established for the respective extract or fraction, the results of respiratory activity were equivalent to untreated control and were therefore not shown in Table 1.

\section{Time-kill effect}

In order to determine the microbicidal effect of the most active EtOAc fractions, a time-kill assay was performed in vitro. The results are presented in Table 2.

Data are presented in terms of the $\log _{10} \mathrm{CFU} / \mathrm{ml}$ change and are based on the conventional bactericidal activity standard, that is a $3 \log _{10} \mathrm{CFU} / \mathrm{ml}$ or greater reduction in the viable colony count [30]. Average log reduction in viable cell count in time-kill assay ranged between $4.019 \log _{10}$ to $1.6 \log _{10} \mathrm{CFU} / \mathrm{ml}$ after $24 \mathrm{~h}$ of treatment with $4 \times \mathrm{MBC}$ with EtOAc fraction from aerial parts and $4.003 \log _{10}$ to zero after $24 \mathrm{~h}$ of treatment with $4 \times \mathrm{MBC}$ with EtOAc fraction from roots. Growth inhibition and efficacy of the EtOAc fractions were observed to be dose dependent and time dependent, producing distinct timekill profile for B. cereus ATCC 9634.

\section{Radical scavenging activity $D P P H \cdot$ radical scavenging activity}

The radical scavenging potential of G. urbanum was evaluated by two complementary methods. The free radical scavenging activity, determined by the DPPH • assay, is visualized in Fig. 2. Among all tested extracts, the best scavenging activity was demonstrated for the roots and the aerial parts EtOAc fractions: the values were close to that of the antioxidant agent caffeic acid used as a positive control. Their $\mathrm{EC}_{50}$ values were, respectively, 0.8 and $1.5 \mu \mathrm{g} / \mathrm{ml}$. The inhibitory potency of $n-\mathrm{BuOH}$ fractions was next in line (with $\mathrm{EC}_{50}$ of 4.5 and $3.7 \mu \mathrm{g} / \mathrm{ml}$ for the aerial parts and roots, respectively). The potency of total $\mathrm{MeOH}$ extracts followed. The inhibitory effect of the petroleum ether fractions increased only up to $2.5 \mu \mathrm{g} / \mathrm{ml}$ of concentration. 


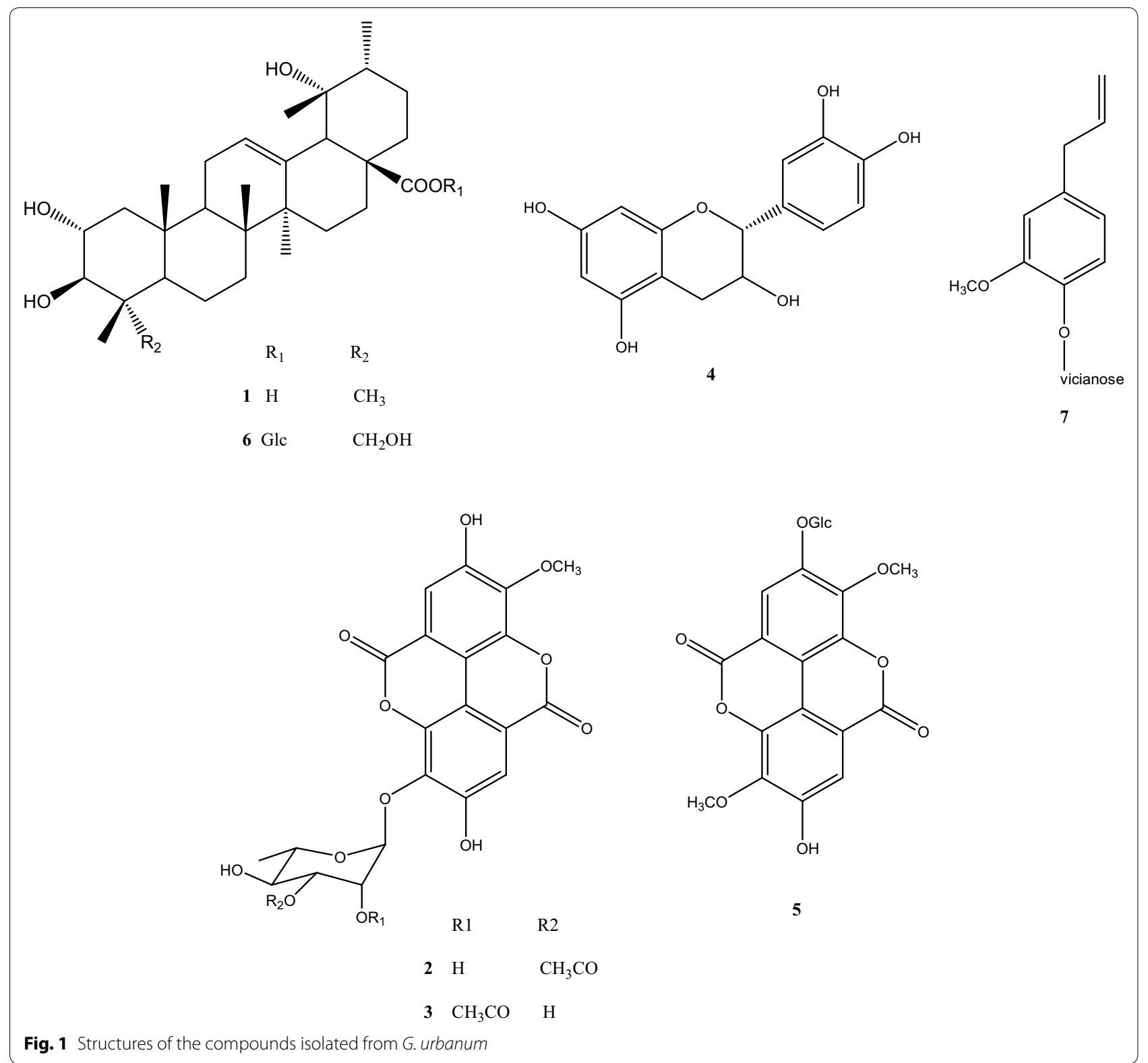

\section{Superoxide anion radical scavenging activity}

Additional investigation of the antiradical activity of the $\mathrm{MeOH}$ extracts from G. urbanum and the fractions thereof was performed in a non-enzymatic system: NBT, methionine and riboflavin. Under these conditions, superoxide anion radicals were generated photochemically. Most of the studied extracts inhibited the development of the color, produced during the reaction between $\mathrm{O}_{2}{ }^{-}$and NBT. The highest scavenging activity was demonstrated by EtOAc fractions from roots and aerial parts, followed by $n-\mathrm{BuOH}$ fractions and then by total $\mathrm{MeOH}$ extracts. The results are visualized in Fig. 3.
Moreover, the studied extracts and fractions suppressed the release of the superoxide anion radical in a dose-dependent manner (Fig. 4). The $50 \% \mathrm{O}_{2}{ }^{-}$scavenging concentrations $\left(\mathrm{IC}_{50}\right)$ of EtOAc fractions from roots and aerial parts were found to be $0.9 \mu \mathrm{g} / \mathrm{ml}$, and of the positive control caffeic acid $0.7 \mu \mathrm{g} / \mathrm{ml}$. On the other hand, both petroleum ether fractions showed no significant changes in $\mathrm{O}_{2}{ }^{-}$scavenging activity when applied in the incubation mixture.

\section{Quantification of total phenolics}

The concentration of the total polyphenolic compounds was determined in $\mathrm{MeOH}$ extracts, petroleum ether, 


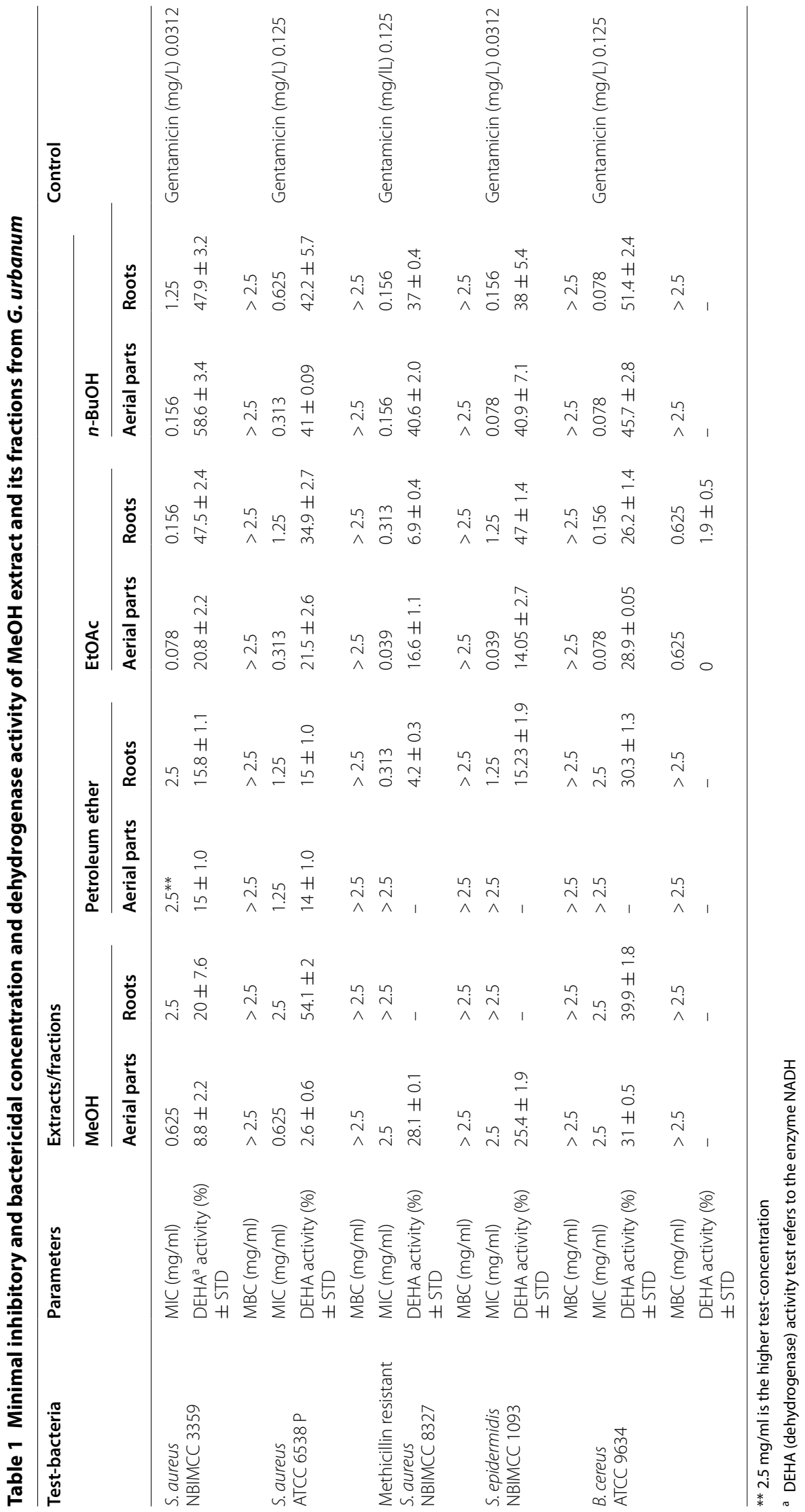


Table 2 In vitro time-kill assay of EtOAc fractions from aerial parts and roots of G. urbanum against B. cereus ATCC 9634

\begin{tabular}{|c|c|c|c|c|c|c|}
\hline \multirow[t]{3}{*}{ Intervals (h) } & \multicolumn{6}{|c|}{ EtOAc fractions } \\
\hline & \multicolumn{3}{|c|}{ Roots $\left(\log _{10}\right)$} & \multicolumn{3}{|c|}{ Aerial parts $\left(\log _{10}\right)$} \\
\hline & MBC & $2 \times M B C$ & $4 \times M B C$ & MBC & $2 \times M B C$ & $4 \times \mathrm{MBC}$ \\
\hline 0 & 3.975 & 3.997 & 4.003 & 4.073 & 4.015 & 4.019 \\
\hline 4 & 3.934 & 3.657 & 3.155 & 3.986 & 3.659 & 3.365 \\
\hline 12 & 3.459 & 3.167 & 1.845 & 3.719 & 3.288 & 2.954 \\
\hline 24 & 2.550 & 1.398 & - & 3.681 & 3.097 & 1.602 \\
\hline
\end{tabular}

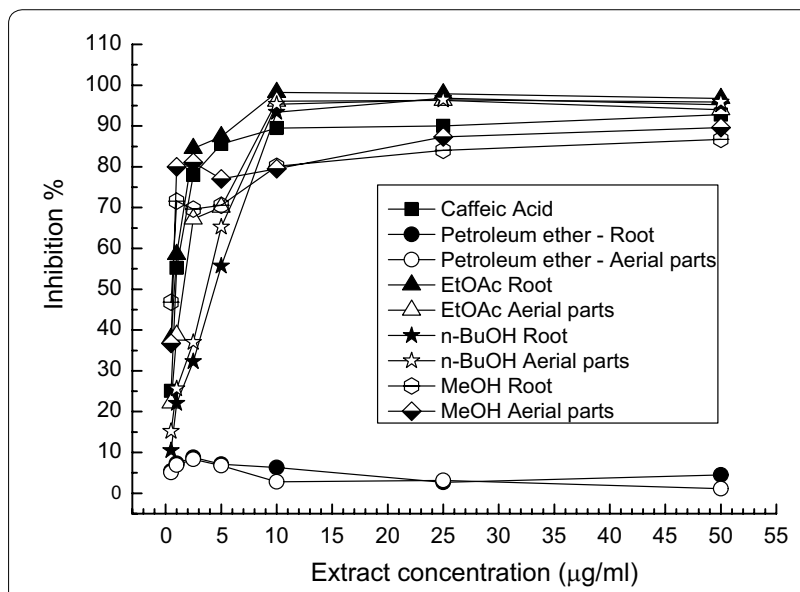

Fig. 2 Free radical scavenging effect of different $\mathrm{MeOH}$ extracts and fractions from G. urbanum (DPPH• assay)

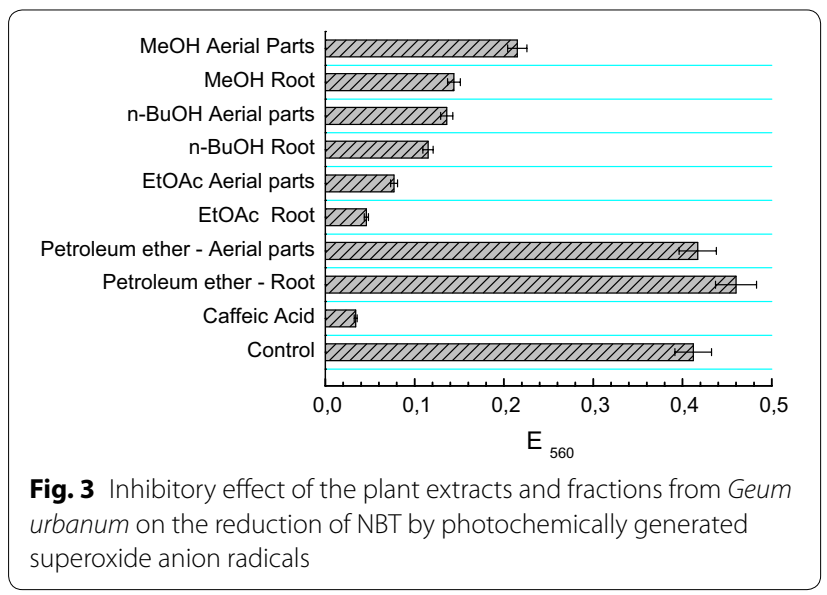

EtOAc and $n-\mathrm{BuOH}$ fractions by the Folin-Ciocalteu method.

The highest content of polyphenol compounds was found in the EtOAc fractions from roots and aerial parts, followed by $n-\mathrm{BuOH}$ and petroleum ether fractions (Table 3). The two petroleum ether fractions contained very low amounts of polyphenolic compounds-from

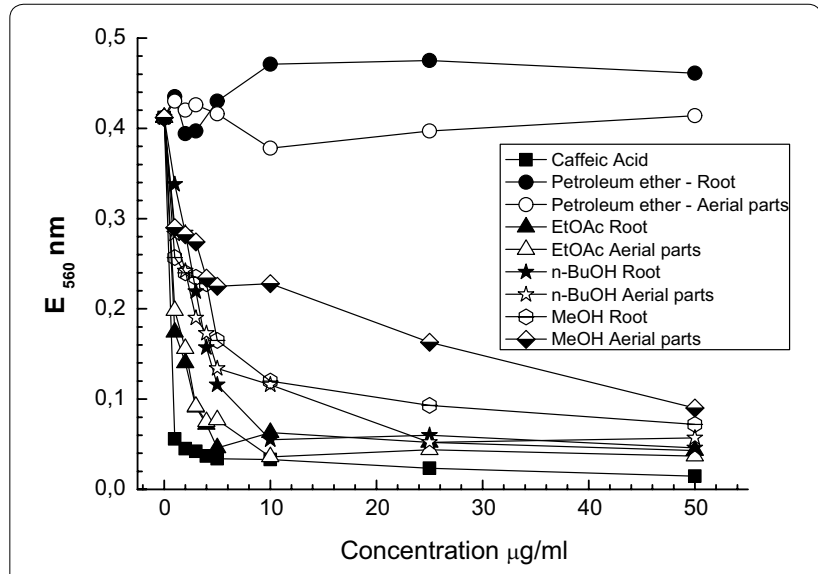

Fig. 4 Dose-dependence of the superoxide anion scavenging effect of the $\mathrm{MeOH}$ extracts and fractions from Geum urbanum

Table 3 Total phenolic content (\% of dry extract) in different extracts and fractions of $G$. urbanum $L$.

\begin{tabular}{lcc}
\hline Extracts/fractions & \multicolumn{2}{l}{ Total phenolics } \\
\cline { 2 - 3 } & Roots & Aerial parts \\
\hline MeOH & $19 \pm 4$ & $11.3 \pm 0.6$ \\
Petroleum ether & $2.8 \pm 0.3$ & $1.0 \pm 0.3$ \\
EtOAc & $61 \pm 9$ & $32 \pm 3$ \\
$n-\mathrm{BuOH}$ & $16.1 \pm 0.3$ & $13 \pm 1$ \\
\hline
\end{tabular}

1 to $2.8 \%$. It is obvious that EtOAc is the best solvent to extract polyphenols from the total $\mathrm{MeOH}$ extracts.

\section{Identification of individual constituents of the EtOAc fraction from roots}

The EtOAc fraction of roots showed the highest antibacterial and radical scavenging activities and the highest content of polyphenolic compounds, thus it was subjected to detailed chemical study. Seven individual compounds were isolated and their structures were elucidated by comparison of their spectral characteristics $\left({ }^{1} \mathrm{H}\right.$ and ${ }^{13} \mathrm{C}$ NMR, MS) with literature data: 
tormentic acid 1 [25], 3-O-methylellagic acid-3'-O- $\alpha$ $3^{\prime \prime}$-O-acetylrhamnopyranoside 2 [26], 3-O-methylellagic acid-3'-O- $\alpha-2^{\prime \prime}-O$-acetylrhamnopyranoside 3 [26], catechin 4 [27], 3,3'-di-O-methylellagic acid-4-O- $\beta$-Dglucopyranoside 5 [28], niga-ichigoside F1 6 [27], and gein 7 [27] (Spectral data of the isolated compounds are presented in Additional file 1).

\section{MIC of individual compounds from EtOAc fraction}

Six isolated compounds from the EtOAc fraction of roots were subjected to MIC determination against E. coli SAIM WF+, C. albicans SAIM 562, S. aureus NBIMCC 3359 and P. aeruginosa NCTC 6749. Results are shown in Table 4. Tormentic acid had bacteriostatic activity against $C$. albicans SAIM 562 and S. aureus NBIMCC 3359 in concentrations, respectively, $500 \mu \mathrm{g} /$ $\mathrm{ml}$ and $125 \mu \mathrm{g} / \mathrm{ml}$. Catechin showed bactericidal effect against S. aureus NBIMCC 3359 and P. aeruginosa NCTC 6749 in concentrations, respectively, 250 and $500 \mu \mathrm{g} / \mathrm{ml}$ (Table 4). 3-O-methylellagic acid-3'-O- $\alpha-2^{\prime \prime}-$ $O$-acetylrhamnopyranoside 3 was isolated in very small amount $(3.8 \mathrm{mg})$ and was not tested.

\section{Discussion}

The increasing antimicrobial resistance during the last decades drove scientist to search for new sources of antimicrobial compounds and more intensively to focus on investigation of various medicinal plants as an opportunity to deal with this burden. In our study, for the first time we explored the antimicrobial properties of the medicinal plant G. urbanum. Total $\mathrm{MeOH}$ extracts of roots and aerial parts of G. urbanum and their fractions obtained by subsequent extraction with petroleum ether, EtOAc and $n-\mathrm{BuOH}$ were studied.

The extracts and fractions obtained were investigated for antibacterial effect on a selected panel of Grampositive and Gram-negative bacterial species. Our data showed that the response of the Gram-positive bacteria varied depending on the strains, wherein the growth of Gram-negative bacteria was not influenced by any of the tested extracts and fractions. The Gram-negative bacteria are considered to be more resistant due to their outer membrane and/or the presence of plasmid genes acting as a barrier to many environmental substances including antimicrobial agents [31]. Regarding the Gram-positive bacterial strains tested in our study, the four EtOAc and $n$ - $\mathrm{BuOH}$ fractions showed stronger antibacterial activity than the total extracts or other fractions. The EtOAc fractions exerted the strongest antibacterial potential and the test strain B. cereus ATCC 9634 was found to be most sensitive. Lower concentration of EtOAc fractions from aerial parts (MIC $78 \mu \mathrm{g} / \mathrm{ml}$ ) and roots (MIC $156 \mu \mathrm{g} /$ $\mathrm{ml}$ ) inhibited the visible growth of the test bacteria and suppressed their respiratory activity up to $26.2-28.9 \%$, whereas higher concentrations $(625 \mu \mathrm{g} / \mathrm{ml})$ exerted bactericidal effect. The EtOAc and $n-\mathrm{BuOH}$ fractions were characterized by high polyphenolic content. Thus, it could be hypothesized that their antibacterial effect is most probably due to the adsorption of polyphenols to bacterial membranes with membrane disruption and subsequent leakage of cellular contents [32] and the generation of hydroperoxides from polyphenols [33].

Antioxidants are compounds involved in the defense mechanism of organisms against pathologies associated to the attack of free radicals [34]. These pathologies can lead to cancer, coronary heart disease, obesity, type 2 diabetes, hypertension, cataract, neurodegenerative diseases, including Alzheimer's and Parkinson's diseases [35]. In our study we used two complementary methods to detect the radical scavenging activity of extracts and fractions of G. urbanum: DPPH• assay based on electron transfer process, and superoxide anion radical scavenging assay based on a hydrogen atom transfer process [36]. The total $\mathrm{MeOH}$ extracts demonstrated some DPPH. scavenging activity. Among all the samples tested, EtOAc fractions from roots and aerial parts showed the highest

Table 4 Antibacterial activity of single compounds ( $\mathrm{mg} / \mathrm{ml}$ ) isolated from $\mathrm{G}$. urbanum

\begin{tabular}{|c|c|c|c|c|}
\hline \multirow[t]{2}{*}{ Compounds } & \multicolumn{4}{|l|}{ Test bacteria } \\
\hline & S. aureus 3359 & P. aeruginosa 6749 & E. coli WF+ & C. albicans 562 \\
\hline Tormentic acid $\mathbf{1}$ & $0.125^{*}$ & $>2.5$ & $>2.5$ & $0.5^{*}$ \\
\hline Catechin 4 & $0.25^{* *}$ & $0.5^{* *}$ & $>2.5$ & $>2.5$ \\
\hline Gein 7 & $>2.5$ & $>2.5$ & $>2.5$ & $>2.5$ \\
\hline Niga-ichigoside F1 6 & $>2.5$ & $>2.5$ & $>2.5$ & $>2.5$ \\
\hline 3,3'-di-O-methylellagic acid-4-O- $\beta$-D-glucopyranoside $\mathbf{5}$ & $>2.5$ & $>2.5$ & $>2.5$ & $>2.5$ \\
\hline 3-O-methylellagic acid-3'-O- $a-3^{\prime \prime}-0$-acetylrhamnopyranoside $\mathbf{2}$ & $>2.5$ & $>2.5$ & $>2.5$ & $>2.5$ \\
\hline
\end{tabular}

$2.5 \mathrm{mg} / \mathrm{ml}$ is the highest test concentration of compounds

* Bacteriostatic activity; ${ }^{* *}$ bactericidal activity 
$\mathrm{DPPH} \cdot$ radical scavenging potential (with $\mathrm{EC}_{50}$ values of 0.8 and $1.5 \mu \mathrm{g} / \mathrm{ml}$, respectively), even better than that of the positive control caffeic acid. In comparison, the study of Owczarek et al. [14] demonstrated that EtOAc fractions of wildly growing G. urbanum, collected from Lodz area, had $\mathrm{EC}_{50}$ values of 3.16 and $4.18 \mu \mathrm{g} / \mathrm{ml}$ for the root and aerial parts, respectively. The highest DPPH• radicals inhibition percentage was found for the EtOAc fractions which demonstrated also the highest total phenolic content (Table 3). This is an expected result, because the Folin-Ciocalteu method is based on an oxidation-reduction reaction and, as such, can be considered another method for antioxidant evaluation [37]. The $n-\mathrm{BuOH}$ fractions also demonstrated high antioxidant activity (about $80 \%$ of the EtOAc activity) (Fig. 2), although their phenolic content is lower (about 4 fold) as compared to the EtOAc. As is known, different phenolic compounds have different responses in the assay method [38]. Thus, G. urbanum $\mathrm{MeOH}$ extracts and fractions thereof (except petroleum ether fraction) contain phytochemical constituents that are capable of scavenging free radicals to prevent the potential damage.

As a complementary method for antiradical activity, the superoxide anion radical scavenging test was applied. Superoxide anion radical is one of the strongest agents damaging living cells, specifically because of its participation in the formation of more powerful and dangerous hydroxyl radicals as well as singlet oxygen, both of which contribute to oxidative stress [39]. The results of our study revealed that EtOAc and $n-\mathrm{BuOH}$ fractions of $\mathrm{MeOH}$ extracts had effective capacity of scavenging for superoxide radical (Fig. 3) Furthermore, superoxide scavenging activity was found to be high in EtOAc fractions in a concentration dependent manner. The superoxide scavenging activity correlated also with total phenolic content (Table 3), thus, suggesting its antioxidant potential. Recent studies have shown that polyphenols contribute significantly to the superoxide anion radical scavenging activity of medicinal plants $[39,40]$.

In general, our studies demonstrated that EtOAc fractions from aerial parts and roots from G. urbanum were characterized by the highest antibacterial and antiradical activity, and the highest amount of total phenolics. For this reason, we tried to isolate some individual constituents of the EtOAc fraction of the roots and evaluate their contribution to the observed activities. We isolated and identified 7 individual compounds from the EtOAc fraction of $\mathrm{MeOH}$ extract of G. urbanum roots. Two of them are the well known G. urbanum constituents, catechin 4 and gein 7 . In addition, we found two acetylated ellagic acid rhamnosides, new for the genus Geum-3-O-methylellagic acid-3'-O- $\alpha$ 3 "-O-acetylrhamnopyranoside 2 and 3-O-methylellagic acid- $3^{\prime}-O-\alpha-2^{\prime \prime}-O$-acetylrhamnopyranoside 3 , and three compounds, new for the species G. urbanum: 3,3'-di$O$-methylellagic acid-4- $O-\beta$-D-glucopyranoside 5 and the triterpenoids tormentic acid $\mathbf{1}$ and niga-ichigoside F1 6 . The compounds isolated were tested for their antimicrobial activity (Table 4). Catechin 1 showed some activity against $S$. aureus and $P$. aeruginosa, while tormentic acid was active against $S$. aureus and $C$. albicans.

Catechin (flavan-3-ol) 4 [41] was isolated earlier from G. urbanum L. [12] and G. iranicum [27]. Catechin, isolated from the crude cinnamon stick extract was inactive against B. cereus, L. monocytogenes, S. aureus, E. coli, Salmonella anatum [42]. In contrast, a bactericidal effect of catechin against $S$. aureus and $P$. aeruginosa was observed in our study.

The pentacyclic triterpene tormentic acid $\mathbf{1}$ was isolated earlier from G. rivale [43] and G. japonicum [44]. This acid has demonstrated anticancer, anti-inflammatory and antiatherogenic properties [45-47] and potential in the prevention or treatment of atherosclerosis [48]. According to Jovel et al. [49] tormentic acid did not exhibit antibacterial activity against MRSA. In our study we found that this compound possessed bacteriostatic effect against $S$. aureus and antifungal activity against $C$. albicans.

The other isolated compounds were inactive against the test microorganisms in concentrations up to $2.5 \mathrm{mg} / \mathrm{ml}$. Nevertheless, there are literature data claiming that some of them possess other useful activities.

Gein 7 is a phenolic glycoside from the group of phenylpropanoids [3]. It was isolated before from G. iranicum [27], G. japonicum [50] and G. urbanum [11]. So far, there is no evidence that it exhibits any antibacterial activity [27].

Niga-ichigoside F1 6, a triterpene glycoside [51], was isolated from G. japonicum [12, 50, 52] and G. rivale [43]. Cheng et al. [53] reported that this compound enhanced the efficacy of cardiogenic differentiation of endogenous bone marrow derived from mesenchymal stem cells. It possesses also anti-inflammatory and antinociceptive action [54].

3,3'-di-O-methylellagic acid-4-O- $\beta$-D-glucopyranoside 5 was isolated earlier from G. japonicum [1], but to the best of our knowledge, no literature data on biological activity of this compound are available.

The acetylated rhamnosides of O-methylellagic acid: 3-O-methylellagic acid-3'-O- $\alpha-3^{\prime \prime}-O-$ acetylrhamnopyranoside $\mathbf{2}$ and 3-O-methylellagic acid-3'-O- $\alpha-2^{\prime \prime}-O$-acetylrhamnopyranoside 3 are known constituents of the stem bark of Eucalyptus globulus but have not been identified in the genus Geum so far. They were found to inhibit lipid peroxidation in rat liver microsomes [26]. In general, ellagic acid rhamnoside 
derivatives are known to inhibit $S$. aureus biofilm formation and improve response to antibiotics [55].

It is known from the literature that often the components in crude extracts or fractions demonstrate high antimicrobial activities when they are applied together as part of the mixture which points to synergistic interactions [56]. Our results suggest that this could be the case with G. urbanum.

\section{Conclusion}

This study showed that Geum urbanum L. has antimicrobial potential against Gram-positive bacteria and high free radical scavenging activity. Ethyl acetate seems to be the best solvents to concentrate antimicrobial and antioxidant compounds from $\mathrm{MeOH}$ extracts of the investigated plant, which confirms previous studies [14]. In addition, individual compounds with biological potential were isolated from the EtOAc root fraction, some of which were found for the first time in the genus Geum and in the species Geum urbanum L. Our results reveal that G. urbanum L. is a perspective medicinal plant and deserves further, more detailed studies.

\section{Additional file}

Additional file 1: Figure $\mathbf{S 1} .{ }^{1} \mathrm{H}$ and ${ }^{13} \mathrm{C}$ NMR spectra of tormentic acid (1) in Pyridine $\mathrm{d}_{5}$. Figure $\mathbf{S 2} .{ }^{1} \mathrm{H}_{1}{ }^{13} \mathrm{C}, \mathrm{HSQC}$ and $\mathrm{HMBC}$ NMR spectra of 3-O-methylellagic acid-3'-O- $a-3^{\prime \prime}-O$-acetylrhamnopyranoside (2) in $\mathrm{CDCl}_{3}: \mathrm{CD}_{3} \mathrm{OD}$ 1:1. Figure $\mathbf{S 3} .{ }^{1} \mathrm{H}$ NMR spectrum of 3-O-methylellagic acid-3'-O-a-2"-O-acetylrhamnopyranoside (3) in $\mathrm{CDCl}_{3}: \mathrm{CD}_{3} \mathrm{OD}$ 1:1. Figure S4. ${ }^{1} \mathrm{H}$ NMR spectrum of cathechin (4) in $\mathrm{CD}_{3} \mathrm{OD}$. Figure S5. ${ }^{1} \mathrm{H}$, HSQC and HMBC NMR spectra of 3,3'-di-O-methylellagic acid-4-O- $\beta$-Dglucopyranoside (5) in DMSO. Figure $\mathbf{S 6} .{ }^{1} \mathrm{H}$ and ${ }^{13} \mathrm{C}$ NMR spectra of nigaichigoside $\mathrm{F} 1$ (6) in $\mathrm{CD}_{3} \mathrm{OD}$. Figure $\mathbf{S 7}{ }^{1} \mathrm{H}$ spectrum of gein (7) in $\mathrm{CD}_{3} \mathrm{OD}$.

\begin{abstract}
Abbreviations
MeOH: methanol; EtOAc: ethyl acetate; $n$-BuOH: $n$-butanol; NBIMCC: National Bank for Industrial Microorganisms and Cell Cultures, Bulgaria; ATCC: American Type Cell Culture Collection, USA; SAIM: Collection of the Stephan Angeloff Institute of Microbiology, Bulgaria; NCTC: National Collection of Type Cultures, England; MHA: Muller Hinton agar; MHB: Muller Hinton broth; MIC: minimal inhibitory concentration; MBC: minimal bactericidal concentration; MTT: 3-(4,5-dimethylthiazolyl-2)-2,5-diphenyltetrazolium bromide; DEHA dehydrogenase activity; DPPH: 1,1-diphenyl-2-picrylhydrazyl; NBT: nitro blue tetrazolium; CC: column chromatography; TLC: thin-layer chromatography; NMR: nuclear magnetic resonance spectroscopy; CFU: colony-forming units.
\end{abstract}

\section{Authors' contributions}

LD and MP prepared the plant extracts and fractions, isolated and characterized individual compounds. VB directed the design of all chemical experiments and analysis. LD, MMZ and IT performed the antimicrobial assays, measured the dehydrogenase activity of bacteria after treatment and participated in the data analysis. HN directed the design of all microbiological tests and the analysis of the data. NK determined the radical scavenging activity. LD and MMZ wrote the manuscript draft. LD, MP, VB, MMZ, IT, HN and NK corrected the manuscript. All authors read and approved the final manuscript.

\section{Author details}

1 Department of Infectious Microbiology, The Stephan Angeloff Institute of Microbiology, Bulgarian Academy of Sciences, Acad. G. Bonchev Str. BI. 26, 1113 Sofia, Bulgaria. ${ }^{2}$ Institute of Organic Chemistry with Centre of Phytochemistry, Bulgarian Academy of Sciences, Acad. G. Bonchev Str. BI.9, 1113 Sofia, Bulgaria.

\section{Acknowledgements}

This work was supported by Grant DFNP-70 of the Bulgarian Academy of Sciences for Lyudmila L. Dimitrova. The colorimetric assays were performed on equipment donated by the Alexander von Humboldt Foundation to Maya M. Zaharieva (Alumni Program "Equipment subsidies").

\section{Competing interests}

The authors declare that they have no competing interests.

\section{Publisher's Note}

Springer Nature remains neutral with regard to jurisdictional claims in published maps and institutional affiliations.

Received: 8 September 2017 Accepted: 26 October 2017

Published online: 07 November 2017

\section{References}

1. Cheng XR, Jin HZ, Qin JJ, Fu JJ, Zhang WD (2011) Chemical constituents of plants from the genus Geum. Chem Biodivers 8:203-222

2. Assyov B, Petrova A, Dimitrov D, Vassilev R (2006) Conspectus of the Bulgarian vascular flora: distribution maps and floristic elements, $3^{\text {rd }}$ edn. Bulgarian Biodiversity Foundation, Sofia. https://www.academia.edu/1219320/ Conspectus_of_the_Bulgarian_vascular_flora._3rd_edition

3. Piwowarski JP, Granica S, Kosiński M, Kiss AK (2014) Secondary metabolites from roots of Geum urbanum L. Biochem Syst Ecol 53:46-50

4. Tita I, Mogosanu GD, Tita MG (2009) Ethnobotanical inventory of medicinal plants from the South-West of Romania. Farmacia 57:141-156

5. Yordanov D, Nikolov P, Boychinov A (1972) Phytotherapy. Treatment with medicinal herbs (book in Russian). Medicine and physical education, Sofia. http://pharmacologylib.ru/books/item/f00/s00/z0000026/index. shtml

6. Vogl S, Picker P, Mihaly-Bison J, Fakhrudin N, Atanasov AG, Heiss EH, Wawrosch C, Reznicek G, Dirsch VM, Saukel J, Kopp B (2013) Ethnopharmacological in vitro studies on Austria's folk medicine-an unexplored lore in vitro anti-inflammatory activities of 71 Austrian traditional herbal drugs. J Ethnopharmacol 149:750-771

7. Feld L, Knudsen GM, Gram L (2012) Bactericidal antibiotics do not appear to cause oxidative stress in Listeria monocytogenes. Appl Environ Microbiol 78:4353-4357

8. Grant SS, Hung DT (2013) Persistent bacterial infections, antibiotic tolerance, and the oxidative stress response. Virulence 4:273-283

9. Kusuma IW, Arung ET, Kim YU (2014) Antimicrobial and antioxidant properties of medicinal plants used by the Bentian tribe from Indonesia. Food Sci Hum Wellness 3:191-196

10. Psenak M, Jindra A, Stano J, Suchy V (1972) Vicianose from the root of Geum urbanum. Planta Med 22:93-96

11. Herrissey H, Cheymol J (1925) Bull Soc Chim Biol 499

12. Gstirner F, Widenmann H (1964) Über Inhaltsstoffe des Rhizoms von Geum urbanum L. Sci Pharm 32:98-104

13. Granica S, Klebowska A, Kosinski M, Piwowarski JP, Dudek MK, Kazmierski S, Kiss AK (2016) Effects of Geum urbanum L. root extracts and its constituents on polymorphonuclear leucocytes functions. Significance in periodontal diseases. J Ethnopharmacol 188:1-12

14. Owczarek A, Gudej J, Olszewska MA (2015) Antioxidant activity of Geum rivale L. and Geum urbanum L. Acta Pol Pharm 72:1239-1244

15. Watts JL (2008) Performance standards for antimicrobial disk and dilution susceptibility tests for bacteria isolated from animals: approved standard. CLSI 3:M31-A33

16. Zheleva-Dimitrova D, Gevrenova R, Zaharieva MM, Najdenski H, Ruseva S, Lozanov V, Balabanova V, Yagi S, Momekov G, Mitev V (2017) HPLC-UV and LC-MS analyses of acylquinic acids in Geigeria alata (DC) Oliv. \& Hiern. and their contribution to antioxidant and antimicrobial capacity. Phytochem Anal 28:176-184 
17. Cosentino S, Tuberoso CIG, Pisano B, Satta M, Mascia V, Arzedi E, Palmas F (1999) In-vitro antimicrobial activity and chemical composition of Sardinian thymus essential oils. Lett Appl Microbiol 29:130-135

18. Balouiri M, Sadiki M, Ibnsouda SK (2016) Methods for in vitro evaluating antimicrobial activity: a review. J Pharm Biomed Anal 6:71-79

19. Bruggisser R, Von Daeniken K, Jundt G, Schaffner W, Tullberg-Reinert H (2002) Interference of plant extracts, phytoestrogens and antioxidants with the MTT tetrazolium assay. Planta Med 68:445-448

20. Han M, Li J, Tan Q, Sun Y, Wang Y (2010) Limitations of the use of MTT assay for screening in drug discovery. J Chin Pharmaceu Sci 19:195-200

21. Riss T (2014) Is your MTT assay really the best choice?. http://worldwide. promega.com/resources/pubhub/is-your-mtt-assay-really-the-bestchoice/. Accessed 15 May 2017

22. Olajuyigbe OO, Afolayan AJ (2012) In vitro antibacterial and time-kill assessment of crude methanolic stem bark extract of Acacia mearnsii De Wild. against bacteria in Shigellosis. Molecules 17:2103-2118

23. Murthy NK, Pushpalatha KC, Joshi CG (2011) Antioxidant activity and phytochemical analysis of endophytic fungi isolated from Lobelia nicotianifolia. J Chem Pharm Res 3:218-225

24. Beauchamp C, Fridovich I (1971) Superoxide dismutase: improved assays and an assay applicable to acrylamide gels. Anal Biochem 44:276-287

25. Park SH, Oh SR, Ahn KS, Kim JG, Lee HK (2002) Structure determination of a new lupane-type triterpene, tiarellic acid, isolated from Tiarella polyphylla. Arch Pharm Res 25:57-60

26. Kim JP, Lee IK, Yun BS, Chung SH, Shim GS, Koshino H, Yoo ID (2001) Ellagic acid rhamnosides from the stem bark of Eucalyptus globulus. Phytochem 57:587-591

27. Shahani S, Monsef-Esfahani HR, Saeidnia S, Saniee P, Siavoshi F, Foroumadi A, Samadi N, Gohari AR (2012) Anti-Helicobacter pylori activity of the methanolic extract of Geum iranicum and its main compounds. Z Naturforsch C Biosci 67:172-180

28. Pakulski G, Budzianowski J (1996) Ellagic acid derivatives and naphthoquinones of Dionaea muscipula from in vitro cultures. Phytochem 41:775-778

29. Burdock TJ, Brooks MS, Ghaly AE (2011) A dehydrogenase activity test for monitoring the growth of Streptomyces venezuelae in a nutrient rich medium. J Bioprocess Biotech 1:1-10

30. Pankey GA, Sabath LD (2004) Clinical relevance of bacteriostatic versus bactericidal mechanisms of action in the treatment of Gram-positive bacterial infections. Clin Infect Dis 38:864-870

31. Teanpaisan R, Kawsud P, Pahumunto N, Puripattanavong J (2017) Screening for antibacterial and antibiofilm activity in Thai medicinal plant extracts against oral microorganisms. J Tradit Complement Med 7:172-177

32. Ikigai H, Nakae T, Hara Y, Shimamura T (1993) Bactericidal catechins damage the lipid bilayer. BBA Biomemb 1147:132-136

33. Akagawa M, Shigemitsu T, Suyama K (2003) Production of hydrogen peroxide by polyphenols and polyphenol-rich beverages under quasiphysiological conditions. Biosci Biotech Biochem 67:2632-2640

34. Pisoschi AM, Negulescu GP (2011) Methods for total antioxidant activity determination: a review. Biochem Anal Biochem 1:1-10

35. Halvorsen BL, Holte K, Myhrstad MCW, Barikmo I, Hvattum E, Remberg SF, Wold AB, Haffner K, Baugerød H, Andersen LF (2002) A systematic screening of total antioxidants in dietary plants. J Nutr 132:461-471

36. Badarinath AV, Rao KM, Chetty CMS, Ramkanth S, Rajan TVS, Gnanaprakash K (2010) A review on in vitro antioxidant methods: comparisions, correlations and considerations. Int J Pharm Tech Res 2:1276-1285

37. Prior RL, Wu X, Schaich K (2005) Standardized methods for the determination of antioxidant capacity and phenolics in foods and dietary supplements. J Agric Food Chem 53:4290-4302

38. Satue-Gracia MT, Heinonen M, Frankel EN (1997) Antioxidant activity of anthocyanin in LDL and lecithin liposome systems. J Agric Food Chem 45:3362-3367
39. Saeed N, Khan MR, Shabbir M (2012) Antioxidant activity, total phenolic and total flavonoid contents of whole plant extracts Torilis leptophylla $\mathrm{L}$. BMC Complement Altern Med 12:221

40. Gangwar M, Gautam MK, Sharma AK, Tripathi YB, Goel RK, Nath G (2014) Antioxidant capacity and radical scavenging effect of polyphenol rich Mallotus philippenensis fruit extract on human erythrocytes: an in vitro study. Sci World J 2014:1-12

41. Mendoza-Wilson AM, Glossman-Mitnik D (2006) Theoretical study of the molecular properties and chemical reactivity of $(+)$-catechin and (-)-epicatechin related to their antioxidant ability. J Mol Struc THEOCHEM 761:97-106

42. Shan B, Cai YZ, Brooks JD, Corke H (2007) Antibacterial properties and major bioactive components of cinnamon stick (Cinnamomum burmannii): activity against foodborne pathogenic bacteria. J Agric Food Chem 55:5484-5490

43. Panizzi L, Catalano S, Miarelli C, Cioni PL, Campeol E (2000) In vitro antimicrobial activity of extracts and isolated constituents of Geum rivale. Phytother Res 14:561-563

44. Xu HX, Zeng FQ, Wan M, Sim KY (1996) Anti-HIV triterpene acids from Geum japonicum. J Nat Prod 59:643-645

45. Ivorra MD, Paya M, Villar A (1988) Hypoglycemic and insulin release effects of tormentic acid: a new hypoglycemic natural product. Planta Med 54:282-286

46. Jian CX, Li MZ, Zheng WY, He Y, Ren Y, Wu ZM, Fan QS, Hu YH, Li CJ (2015) Tormentic acid inhibits LPS-induced inflammatory response in human gingival fibroblasts via inhibition of TLR4-mediated NF-kB and MAPK signalling pathway. Arch Oral Biol 60:1327-1332

47. Loizzo MR, Bonesi M, Passalacqua NG, Saab A, Menichini F, Tundis R (2013) Antiproliferative activities on renal, prostate and melanoma cancer cell lines of Sarcopoterium spinosum aerial parts and its major constituent tormentic acid. Anti Cancer Agents Med Chem 13:768-776

48. Wang YL, Sun GY, Zhang Y, He JJ, Zheng S, Lin JN (2016) Tormentic acid inhibits $\mathrm{H}_{2} \mathrm{O}_{2}$-induced oxidative stress and inflammation in rat vascular smooth muscle cells via inhibition of the NF-KB signaling pathway. Mol Med Rep 14:3559-3564

49. Jovel EM, Zhou XL, Ming DS, Wahbe TR, Towers GHN (2007) Bioactivityguided isolation of the active compounds from Rosa nutkana and quantitative analysis of ascorbic acid by HPLC. Can J Physiol Pharmacol 85:865-871

50. Shigenaga S, Kouno I, Kawano N (1985) Triterpenoids and glycosides from Geum japonicum. Phytochem 24:115-118

51. Niero R, Cechinel Filho V, Souza MM, Montanari JL, Yunes RA, Delle Monache F (1999) Antinociceptive activity of niga-ichigoside F1 from Rubus imperialis. J Nat Prod 62:1145-1146

52. Yoshida T, Maruyama Y, Memon MU, Shingu T, Okuda T (1985) Gemins D, E and F, ellagitannins from Geum japonicum. Phytochem 24:1041-1046

53. Cheng L, Chen H, Yao X, Qi G, Liu H, Lee K, Lee K, Zhang J, Chen S, Lin X (2009) A plant-derived remedy for repair of infarcted heart. PLOS ONE 4:e4461

54. Choi J, Lee KT, Ha J, Yun SY, Ko CD, Jung HJ, Park HJ (2003) Antinociceptive and antiinflammatory effects of Niga-ichigoside F1 and 23-hydroxytormentic acid obtained from Rubus coreanus. Biol Pharm Bull 26:1436-1441

55. Quave CL, Estévez-Carmona M, Compadre CM, Hobby G, Hendrickson H, Beenken KE, Smeltzer MS (2012) Ellagic acid derivatives from Rubus ulmifolius inhibit Staphylococcus aureus biofilm formation and improve response to antibiotics. PLOS ONE 7:e28737

56. Eloff JN (1998) Which extractant should be used for the screening and isolation of antimicrobial components from plants? J Ethnopharmacol $60: 1-8$ 